\title{
Implementing Treatment Sequences to Promote Reduction of DBPs in Small Drinking Water Systems
}

\author{
C. M. Roberts • E. C. Inniss
}

Received: 20 April 2013 / Accepted: 21 February 2014 /

Published online: 8 March 2014

(C) The Author(s) 2014. This article is published with open access at Springerlink.com

\begin{abstract}
The performance of three drinking water treatment sequences found in small community systems in reducing disinfection by-product precursor concentrations and the corresponding disinfection by-product formation potential was evaluated. Raw water quality and its potential for effective removal were characterized by the specific ultraviolet absorbance (SUVA) components of absorbance of ultraviolet light at $254 \mathrm{~nm}$ wavelength (UV254) and dissolved organic carbon (DOC). The results demonstrate that, for the source water qualities tested (hydrophobic SUVA with moderate DOC content, 2.0 to $4.8 \mathrm{~L} /(\mathrm{mg} . \mathrm{m})$ and 4.1 to $6.3 \mathrm{mg}$ $\mathrm{DOC} / \mathrm{L}$ ), there was a tendency to produce a higher percentage of total trihalomethane (TTHM) over the five regulated species of haloacetic acid (HAA5). The treatment sequence and chemical selection play a critical role in the ability of a small community system operator to achieve compliance with the concentration of regulated disinfection by-products. For the waters tested ferric chloride coagulants perform better at reducing the higher molecular weight, hydrophobic organic precursors. Powdered activated carbon does not perform as well with these source waters unless its application is followed by a clarification process that effectively forms a sludge blanket. This research provides additional criteria for linking source water quality with treatment sequence for sustainable management of disinfection by-product (DBP) compliance.
\end{abstract}

Keywords Disinfection by-products $\cdot$ Enhanced coagulation/softening $\cdot$ Haloacetic acid . Trihalomethane $\cdot$ Formation potential

\section{Introduction}

According to the website at the United States Environmental Protection Agency (EPA), more than $94 \%$ of America's 156,000 public water systems serve fewer than 10,000 persons. These systems, classified as very small $(0-500)$, small $(501-3,300)$ or medium $(3,301-10,000)$ by the

\footnotetext{
C. M. Roberts

U.S. Army Corps of Engineers, Kansas City District, 601 E. 12th Street, Kansas City, MO 64106, USA

E. C. Inniss $(\bowtie)$

Department of Civil and Environmental Engineering, University of Missouri, E2509 Lafferre Hall,

Columbia, MO 65211, USA

e-mail: innisse@missouri.edu
} 
EPA, face unique financial and operational challenges in supplying drinking water that meets water quality standards. These water systems do not have the large customer base needed to provide the necessary financial assistance and cannot easily develop or access the technical, managerial, and financial resources needed to comply with the tightening EPA regulations and rising customer expectations (USEPA 2008). The need for assistance in small drinking water systems was originally recognized under the Safe Drinking Water Act. New federal regulations continue to greatly affect small communities. If current treatment is not improved, many of these small systems will be out of compliance in the near future and deliver water containing unhealthy levels of disinfection by-products, or DBPs (Chowdhury 2013; MoTAC 2009).

In an effort to develop a methodology for determination of optimal chemical dosing for reducing the amount of DBPs formed in both the water treatment plants and in the distribution systems, three drinking water treatment facilities from small communities in Missouri were selected and tested. Considerations for improving treatment plant performance were based on their sequence of treatment and source water characteristics. The systems chosen all have finished water trihalomethane (THM) and/or haloacetic acid (HAA) levels in excess of Stage 2 Disinfectants and Disinfection By-Products drinking water standards (AWWA 2010).

Natural organic materials (NOM) are present to various degrees in all water supplies. It is a major component of total organic carbon (TOC) concentration and has been identified as the principal precursor in the formation of HAAs and THMs (Liang and Singer 2003; Teixeria et al. 2011). Halogenated DBP formation decreases as the activated or electron rich aromatic content of NOM decreases (Reckhow et al. 1990). The effectiveness of removing NOM varies with the nature of the NOM, such as its molecular weight, charge density, and polarity, and with properties of the raw water such as turbidity and hardness (Bolto et al. 2002). The effectiveness of a given coagulant to remove NOM varies depending upon the active charge density, floc surface area available for adsorption, and the nature of the bonds between the organics and the metal hydroxide flocs (Crozes et al. 1995; Duan et al. 2012; Ho et al. 2013).

Enhanced softening is defined by the EPA as the modification of chemical dosages for the increased removal of DBP precursors during the softening process (Thompson et al. 1997). This process involves lime addition for water softening and the addition of a coagulant. High doses of lime $(200 \mathrm{mg} / \mathrm{L})$ may not be effective enough alone for the removal of DBP precursors due to electrostatic repulsion from the high negative charge density of humic substances and the negatively-charged calcium carbonate crystalline surface. Adding a cationic coagulant (e.g. ferric chloride or liquid alum) can alter the surface character of calcium carbonate precipitates to better remove NOM by adsorption (Uyak et al. 2007; Yan et al. 2008). Duan et al. (2012) conversely show that calcium hydroxide assisted alum coagulation may effectively reduce low molecular weight compounds.

Small community surface waters tend to generate higher concentrations and a wider variability of DBP production than are found with larger systems and therefore need to apply enhanced coagulation treatment strategies to reduce their potential to form DBPs (Chowdhury 2013). Alternatively, other researchers such as Hobson et al. (2010) point to better management of the source water off-take levels as an approach for systems to reduce the amount of NOM taken into the treatment process and subsequently reducing the amount of treatment required. Practically speaking, the research reported here is intended to further demonstrate how the source water characteristics dictate which treatment strategy/chemical choice more effectively reaches the ultimate goal of reducing both absorbance of ultraviolet radiation at $254 \mathrm{~nm}\left(\mathrm{UV}_{254}\right)$ and dissolved organic carbon (DOC) in the setting of a small drinking water system. The understanding of the results of these case studies should provide both designers and facility operators with additional guidance for evaluating which are the more appropriate 
strategies, based on target threshold levels of water quality parameters, for maintaining regulatory compliance.

\section{Materials and Methods}

The testing for each facility was done in two phases. The first phase produced a baseline profile the potential to form DBPs both throughout the mechanical water treatment process and in the distribution system. Specifically, focus was placed on determining which portions of the process provide the best opportunities for modifications to more effectively further remove DBP precursors. Data was collected on DBP and disinfection by-product formation potential $(\mathrm{DBP} f p)$ in addition to other related chemical analyses of select water samples.

The second phase identifies and tests potential options for the facility operator to use to achieve compliance with federal DBP limits. The approach to this phase of the study includes jar testing of higher and/or lower dosages of the chemicals currently being used in the treatment process, testing of alternate sequences of chemical dosing, and testing of alternate chemicals not currently being used. For the data reported here, based on constraints within small system operation, chemical choices are limited to those commonly used by surface water treatment plants. The source water DBP formation potential and precursor numbers determined during selected months of the year were averaged for each facility.

Table 1 provides a comparison of the measured source water quality or raw water (RW) for the systems studied and also compares them to typical values reported in the literature (Qasim et al. 2000). Three types of surface RW were chosen which should represent some of the surface water scenarios typically encountered. The first water is a city lake (CTL). Often used for recreation these water bodies tend to be less influenced by rural activities, such as farming and grazing, and more by urban activities. The second water is a reservoir (AGR), which is similar in function to the lake, but more influenced by agricultural practices. The third surface water is a spring fed river (SFR). These tend to be influenced by higher mineral content during low flows, which lead to higher hardness and alkalinity values. Both CTL and AGR, who draw their raw water from reservoirs, have characteristically higher dissolved organic carbon

Table 1 Typical source or raw water, RW, quality (Qasim et al. 2000) compared to measured influent water characteristics of the systems studied

\begin{tabular}{|c|c|c|c|c|c|}
\hline Constituent & Surface water & Ground water & CTL & AGR & SFR \\
\hline Coliform, MPN/100 mL & 2,000 & 100 & & & \\
\hline $\mathrm{UV}_{254}, \mathrm{abs} / \mathrm{cm}$ & & & $0.20 \pm 0.08$ & $0.30 \pm 0.07$ & $0.08 \pm 0.01$ \\
\hline $\mathrm{DOC}, \mathrm{mg} / \mathrm{L}$ & 3 & 0.5 & $6.23 \pm 0.2$ & $6.25 \pm 0.9$ & $4.12 \pm 0.3$ \\
\hline SUVA, L/(mg.m) & & & 3.2 & 4.8 & 2.1 \\
\hline Hardness, $\mathrm{mg} / \mathrm{L}$ as $\mathrm{CaCO}_{3}$ & 90 & 120 & 65 & 73 & 176 \\
\hline Alkalinity, $\mathrm{mg} / \mathrm{L}$ as $\mathrm{CaCO}_{3}$ & 100 & 150 & 62 & 46 & 168 \\
\hline $\mathrm{pH}$ & 7.5 & 7.5 & $8.03 \pm 0.2$ & $7.7 \pm 0.3$ & $8.23 \pm 0.2$ \\
\hline $\mathrm{TDS}, \mathrm{mg} / \mathrm{L}$ & 150 & 250 & & & \\
\hline Turbidity, NTU & 10 & $<0.5$ & $11.4 \pm 5.6$ & $17.8 \pm 2.4$ & $3.3 \pm 1.2$ \\
\hline TTHM $f p(\mu \mathrm{g} / \mathrm{L})$ & & & $277 \pm 11$ & $405 \pm 162$ & $113 \pm 12$ \\
\hline $\mathrm{HAA} 5 f p(\mu \mathrm{g} / \mathrm{L})$ & & & $158 \pm 26$ & $224 \pm 59$ & $68 \pm 15$ \\
\hline
\end{tabular}

$M P N$ most probable number; TDS total dissolved solids; $C T L$ city lake; $A G R$ agriculture influenced reservoir; $S F R$ spring-fed river 
concentrations $(5.8-7.4 \mathrm{mg} / \mathrm{L})$ and moderate $\mathrm{UV}_{254}$ readings $(0.2-0.3 \mathrm{abs} / \mathrm{cm})$. The SFR yields lower DOC and $\mathrm{UV}_{254}$ numbers. This water is also fairly high in hardness and alkalinity when compared to the other two waters.

\subsection{Process Descriptions}

The treatment facilities studied (Fig. 1) all included second stage flocculation and sedimentation process units followed by filtration and chlorination in a clearwell at the end of their treatment train. They differed, however, in the early stages of treatment. These earlier stages, based on phase 1 testing, have a greater influence on the DBP $f p$ in the treated water (TW).

The CTL facility starts with a reservoir and also uses the preoxidant potassium permanganate $\left(\mathrm{KMnO}_{4}\right)$ for manganese removal. A coagulant and powder activated carbon is added during the coagulation process before sending the water through a Degrémont pulsator solids contact unit (Degrémont 2013). This coagulation-solids contact sequence is the first stage of the treatment process. During the critical third quarter (late summer according to Chowdhury 2013) compliance sampling DBP concentrations in the TW could reach $50 \mu \mathrm{g} T \mathrm{THM} / \mathrm{L}$ and $31 \mu \mathrm{g} \mathrm{HAA5/L.}$

The AGR facility begins with lake water and uses the preoxidant potassium permanganate $\left(\mathrm{KMnO}_{4}\right)$ for manganese removal, and then aerates the water. A carbon contact chamber is present for taste and odor issues and uses powder activated carbon. This is followed by a first stage coagulation, flocculation, and sedimentation. During third quarter (late summer) compliance sampling, DBP concentrations in the TW could reach $135 \mu \mathrm{g}$ TTHM/L and $54 \mu \mathrm{g}$ HAA5/L.

The SFR facility gets its water from a spring-fed river and pumps this water into a reservoir. This is followed by first stage coagulation, flocculation, and sedimentation for lime softening in an upflow circular clarifier. During third quarter (late summer) compliance sampling DBP concentrations in the TW could reach $173 \mu \mathrm{g}$ TTHM/L and $56 \mu \mathrm{g}$ HAA5/L.

\subsection{Materials}

Simulation of the first stage of treatment at each of these facilities was conducted (jar testing) to determine the extent of the removal of natural organic matter (precursors for DBP

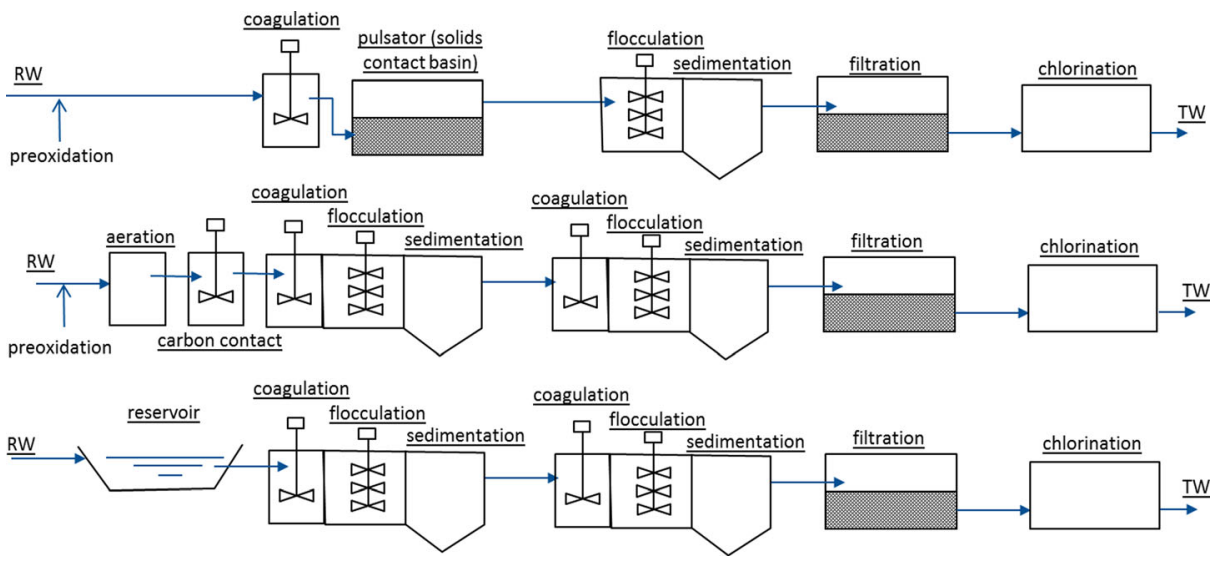

Fig. 1 Treatment process sequences for CTL (top), AGR (middle), and SFR (bottom). $R W$ raw water; $T W$ treated water; $C T L$ city lake; $A G R$ agriculture influenced reservoir; $S F R$ spring-fed river 
production) measured by DOC and $\mathrm{UV}_{254}$. Both haloacetic acid formation potential (HAA5 $f p$ ) and total trihalomethane formation potential (TTHM $f p$ ) were also measured to correlate the precursor reductions to DBP compliance efforts.

\subsubsection{Natural Water Collection and Storage}

Twenty liters of water (in carboys) were collected from each type of water source between December 2009 and May 2010. All carboys were pre-cleaned with distilled water. Water samples were collected and delivered to the laboratory within $24 \mathrm{~h}$ and refrigerated in the dark at $4{ }^{\circ} \mathrm{C}$.

\subsubsection{Reagents}

The chemical reagents and concentrations used in these experiments are based upon the chemicals used at each facility at the time of sampling. These included ferric (Fe) and aluminum $(\mathrm{Al})$ coagulants, cationic polymers, powder activated carbon $(\mathrm{C})$, soda ash (sodium carbonate), lime, baking soda (sodium bicarbonate), and magnesium hydroxide $\left(\mathrm{Mg}_{2}(\mathrm{OH})\right)$.

\subsubsection{Jar Testing}

Experiments are run following a modified version of the standard jar test procedure (ASTM Standard D2035 (ASTM International 2008)). Six 2-1 capacity square beakers (Bker ${ }^{2}$, WU99520-50, Cole Parmer) are filled with $1 \mathrm{~L}$ of raw water from the treatment facility and dosed with prescribed concentrations of chemicals. Turbidity, $\mathrm{UV}_{254}$, and dissolved organic carbon (DOC) are tested for in each sample as well as initial and final $\mathrm{pH}$.

\subsection{Analytical Methods}

These waters were then analyzed to determine the 24-h chlorine demand. The determined demand plus approximately $1 \mathrm{mg} / \mathrm{L}$ excess chlorine was added to each water so that TTHM $f p$ and HAA5 $f p$ could be found following the uniform formation conditions procedure (Summers et al. 1996). Raw water samples without chemical additions followed the same procedure as the other jars at the time of testing and serve as a control or baseline sample to which the treated water samples may be compared.

$U V_{254}$ analysis $\mathrm{UV}_{254}$ absorbance measurements indicate aromatic organic content (Standard Methods 5910 B). Treated water samples from each of the jars are filtered through a $0.45 \mu \mathrm{m}$ glass fiber filter disk (FisherBrand 09-719-2E), poured into a $1 \mathrm{~cm}$ quartz cell (Fischer Scientific \#14385902C), and then run on a UV-Visible Spectrophotometer (Cary 50) at a wavelength of $254 \mathrm{~nm}$.

DOC Analysis To quantify the amount of natural organic matter in a water source, DOC analysis is performed (Standard Methods 5310 B: high temperature combustion method (APHA et al. 1998)). DOC analysis was performed on a Shimadzu TOC-Vcpn instrument with an ASI-V autosampler.

Turbidity Standard Method 2130B (APHA et al. 1998) was followed to measure turbidity using a Hach 2100P turbidimeter.

Alkalinity Alkalinity was performed following Standard Method 2320 B (APHA et al. 1998). 
THM Analysis THM formation potential concentrations were determined by a gas chromatograph (Varian, Model 3800)/mass spectrometer (Varian, Saturn 3800) equipped with a Tekmar 300 purge and trap concentrator following EPA Method 524.2.

HAA5 Analysis The formation potential concentrations of the five (5) regulated species of HAAs were determined by using a liquid/liquid extraction derivation GC method following EPA Method 552.2.

In a study by DeWolfe et al. (2003), pre-neutralized coagulants, such as aluminum chlorohydrate $(\mathrm{ACH})$ or polyaluminum chloride $(\mathrm{PACl})$ have been shown most effective for spring water with very low TOC and moderate alkalinity. $\mathrm{ACH}$, alum, and $\mathrm{PACl}$ were most effective for charge-neutralization for water from a surface reservoir with moderate TOC, low SUVA, and low alkalinity. Alum and ferric chloride has been shown to work best for raw water that was high in TOC and SUVA with low alkalinity.

\subsection{Consideration of DOC and $\mathrm{UV}_{254}$ as Control Parameters}

For each of the waters, UV254 and DOC data was collected and compiled throughout the study. Since SUVA is calculated from (UV254 (abs/cm)*100 cm/m)/DOC $(\mathrm{mg} / \mathrm{L})$ to yield a result in L/mg m, UV254 readings multiplied by 100 are plotted along the $y$-axis versus DOC readings along the x-axis. The slope of the best fit line drawn on this graph is the SUVA trend for each water. A $45^{\circ}$ line is drawn on the graph to indicate the slope of unity corresponding to a SUVA equal to one. Higher SUVA values (greater than 1) are more susceptible to reduction by traditional coagulation.

\subsection{Specific System Phase II Testing}

\subsubsection{City Lake, CTL}

For CTL, 58 different jar test combinations were run. The chemical choices were based off of their current chemical usage and alternatives to the current chemicals. Liquid alum (designated as $\mathrm{Al}$ in later Figure captions) is currently used at the facility $(29 \mathrm{mg} / \mathrm{L})$ as a coagulant for turbidity and the removal of organics. Current concentration, lower concentration $(14.5 \mathrm{mg} / \mathrm{L})$, and several higher concentration $(50,100,150 \mathrm{mg} / \mathrm{L})$ were tested to verify the most favorable dosage for DBP reduction. Ferric chloride (designated as Fe in later figures) was tested as a coagulant alternative to determine if it was more effective than alum. Both were varied in dosage to determine optimal yield. Concentrations tested followed a similar pattern for liquid alum. Sodium carbonate (or soda ash) is currently used at the facility $(77.5 \mathrm{mg} / \mathrm{L}$ ) as a stabilizer to raise the water's alkalinity. Magnesium hydroxide and sodium bicarbonate were used as alternative chemicals to determine the most efficient stabilizer. A typical dosage $(17 \mathrm{mg} / \mathrm{L})$ for a drinking water treatment facility was tested. A polymer (HyperIon 1090; $3.4 \mathrm{mg} / \mathrm{L}$; designated as poly in later captions) is currently used as a coagulant aid for greater organics removal. It was tested to determine if it was efficient in the process at various doses $(2,3.4,6,8 \mathrm{mg} / \mathrm{L})$. Lime was used as an alternative chemical to determine the effectiveness of an increased $\mathrm{pH}$ in the treatment system. Dosages $(60$, $180,300 \mathrm{mg} / \mathrm{L}$ ) were chosen in order to achieve incremental $\mathrm{pH}$ values from 8 to 11 . Powder Activated Carbon (designated as simply $\mathrm{C}$ in later captions) was tested to determine the efficiency in the treatment process and if it could be improved at different dosages (24 versus $48 \mathrm{mg} / \mathrm{L}$ ). 


\subsubsection{Agriculture-Influenced Reservoir, AGR}

An initial 30 tests were run at AGR drinking water plant in July and August 2009. Alum + acid $(60 \mathrm{mg} / \mathrm{L})$ was tested to determine the efficiency in the current treatment process as a coagulant for turbidity and organics removal. Ferric chloride (30, $60 \mathrm{mg} / \mathrm{L})$ and liquid alum $(20,30,40$, $50,60,70,80,90,100,110 \mathrm{mg} / \mathrm{L}$ ) were tested as alternative coagulants. Polymers (Robin 120 $(4,4.5 \mathrm{mg} / \mathrm{L})$ and $\mathrm{AC} 100(5.6,10,15 \mathrm{mg} / \mathrm{L}))$ were tested for efficiency as coagulant aids. Lime $(100 \mathrm{mg} / \mathrm{L})$ was tested to determine if the treatment process could efficiently reduce organic matter by adsorption by increasing the $\mathrm{pH}$. Soda ash $(100 \mathrm{mg} / \mathrm{L})$ was tested as an alternative chemical to lime using the same dosage. Magnesium hydroxide $(7.3,8 \mathrm{mg} / \mathrm{L})$ was tested to determine its effectiveness as a stabilizer. Baking soda (sodium bicarbonate; $7.3 \mathrm{mg} /$ L) was tested as an alternative stabilizer. AquaNuChar carbon $(30 \mathrm{mg} / \mathrm{L})$ was tested to determine its current effectiveness for NOM removal by adsorption. WPH carbon $(10,23$, $35 \mathrm{mg} / \mathrm{L}$ ) was tested as an alternative carbon to see if it was more efficient at the same or lower dosages.

\subsubsection{Spring-Fed River, SFR}

For SFR, 31 different jar test combinations were run. Various chemical combinations were used to determine which would be the most effective. These chemicals were chosen in order to improve on current treatment facility performance. Sodium aluminate $(8 \mathrm{mg} / \mathrm{L})$ is used as a coagulant for turbidity and organics removal. It was tested to determine its current effectiveness in the treatment process. Ferric chloride and liquid alum were tested as alternative coagulants. Sodium aluminate is typically only used in small concentrations, so ferric chloride and liquid alum were tested at slightly higher doses $(50 \mathrm{mg} / \mathrm{L})$. In addition, enhanced treatment was tested using 100,150 , and $200 \mathrm{mg} / \mathrm{L}$ of coagulant. Lime is used to remove hardness in the water and was tested at its current concentration $(130 \mathrm{mg} / \mathrm{L})$ to determine effectiveness for hardness removal and also organics removal. Lower $(60 \mathrm{mg} / \mathrm{L})$ and higher dosages (180, $300 \mathrm{mg} / \mathrm{L}$ ) were tested to determine the optimal $\mathrm{pH}$ and lime dosage. Carbon was tested to determine if it was efficient in the treatment process for DBP precursor reduction. A small dosage $(9 \mathrm{mg} / \mathrm{L})$ was tested due to system limitations.

\section{Results and Discussion}

\subsection{Use of DOC and $\mathrm{UV}_{254}$ as Control Parameters}

In an effort to determine whether SUVA (specific ultraviolet absorbance used to detect the aromatic character of dissolved organic matter; Bourbonniere 2009) values are an appropriate measure of treatment effectiveness at reducing DBP formation potential the trend of DOC versus $U_{254}$ reduction is plotted (Fig. 2). Chow et al. (2009) and other researchers suggest that a reduction in SUVA should yield a reduction in DBP formation potential. The extent of that reduction may be a function of the differential UV spectroscopy or rather the achievement of a preferential change in SUVA (Ho et al. 2013). This preferential change requires a modification of both the DOC and the $\mathrm{UV}_{254}$ values. How best to achieve these reductions is a function of the initial water quality. The slope of the line presented in Fig. 2 indicates the degree of treatability of the source water. Higher slope (CTL and AGR) indicates more susceptibility to treatment with enhanced coagulation to reduce DBP precursors (Teixeria et al. 2011). 


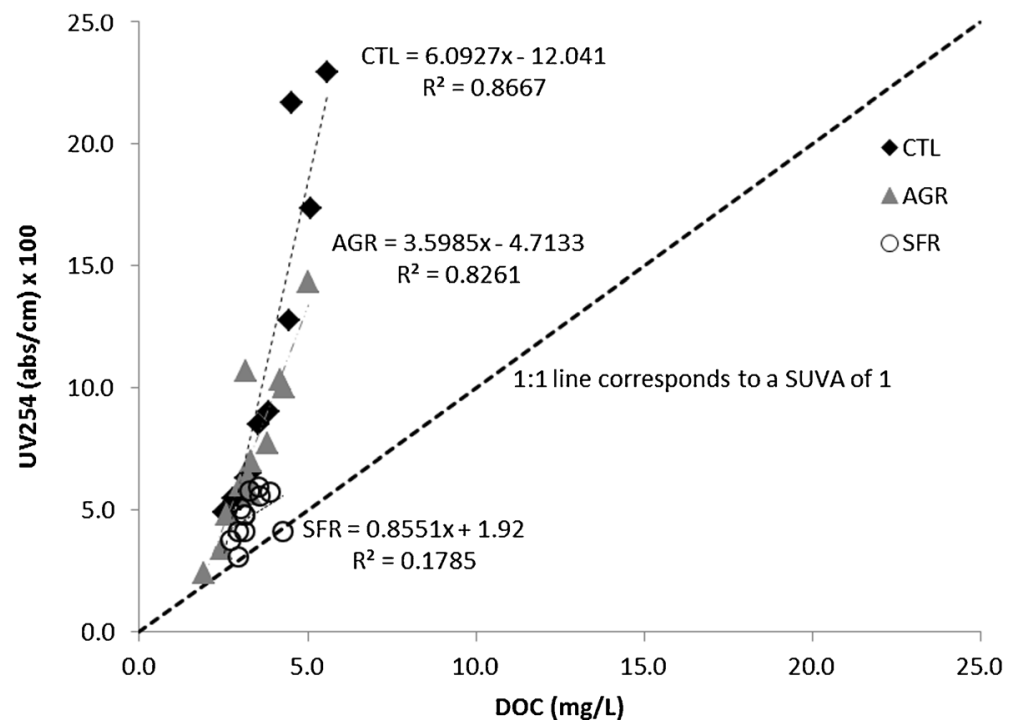

Fig. $2 \mathrm{UV}_{254}$ versus DOC results from the treatment of each of the waters. Since SUVA values are based on the calculation of (UV254)*(100)/DOC, the slopes of the lines shown is the SUVA values and a line showing a $\mathrm{SUVA}=1$ is also provided

As guidance to facility operators on how they may stay in compliance the level the $\mathrm{UV}_{254}$ and DOC needs to be reduced in order to get the DBPs below the maximum contaminant level (MCL) may be found in Fig. 3. $\mathrm{UV}_{254}$ and DOC may be measured more easily at the treatment facility than DBP concentrations. Figure 3 shows the trends of DOC and $\mathrm{UV}_{254}$ values and corresponding TTHM $f p$ for CTL, AGR, and SFR, respectively. Based on these results their compliance may be best achieved if the treatment strategy can get the DOC and the $\mathrm{UV}_{254}$

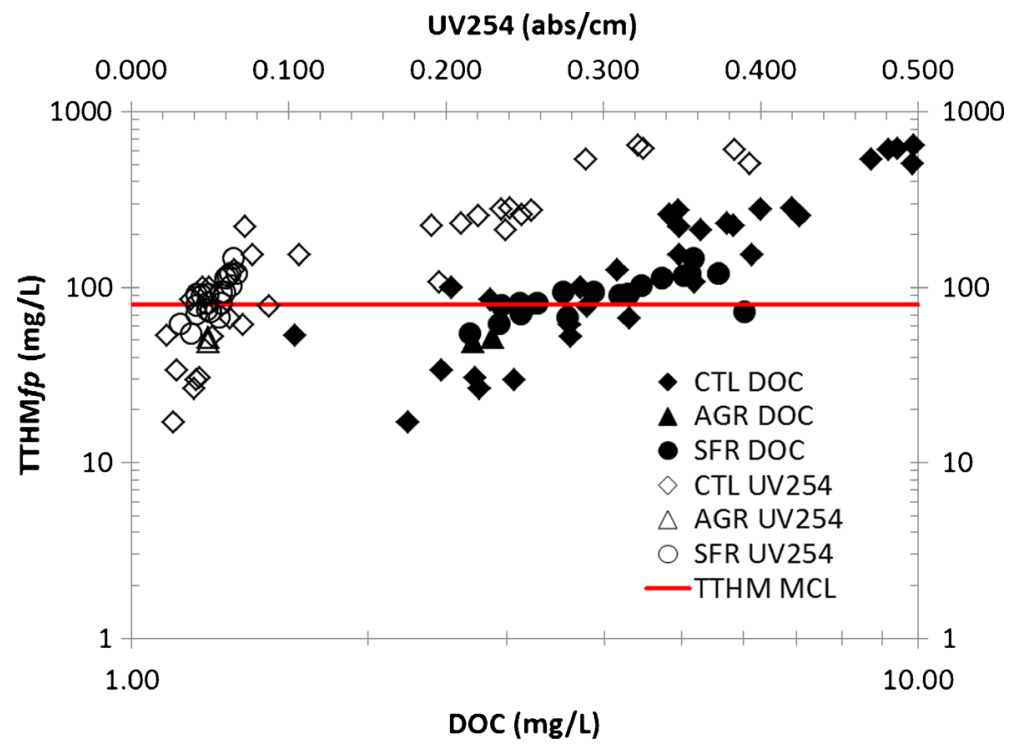

Fig. 3 DOC and $\mathrm{UV}_{254}$ versus TTHM $f p$ 
down to the following levels for each of the facilities: CTL (DOC $<3 \mathrm{mg} / \mathrm{L} ; \mathrm{UV}_{254}<0.05$; $\mathrm{SUVA}<1.7)$, AGR $\left(\mathrm{DOC}<3 \mathrm{mg} / \mathrm{L} ; \mathrm{UV}_{254}<0.06\right.$; $\left.\mathrm{SUVA}<2.0\right)$, and $\mathrm{SFR}(\mathrm{DOC}<3 \mathrm{mg} / \mathrm{L}$; $\mathrm{UV}_{254}<0.04$; SUVA $<1.3$ ). This translates to a change in SUVA (from the RW SUVA) of 1.5 (or $-47 \%$ ) for CTL, 2.8 (or $-58 \%$ ) for AGR, and 0.8 (or $-38 \%$ ) for SFR.

\subsection{Appropriate Treatment Based on Source Water Quality}

\subsubsection{City Lake, CTL}

The water used for these tests was obtained from the raw water just before the addition of permanganate. This site was selected in order to optimize the chemical choices in the first stage rapid mix, flocculation, and settling processes. From the results of the testing shown in Fig. 4, liquid alum (Al) and carbon (C) gave the best results for TTHM and HAA5 formation potential $(f p)$. Only tests 1,4 , and 5 yield both TTHM $f p$ concentrations below $80 \mu \mathrm{g} / \mathrm{L}$ and HAA5 $f p$ less than $60 \mu \mathrm{g} / \mathrm{L}$.

CTL seemed to be most responsive to higher carbon doses or enhanced coagulation. Each of the more promising treatment strategies yielded a lower $\mathrm{pH}$, typically less than 5 without any $\mathrm{pH}$ adjustments. Lower $\mathrm{pH}$ values affect the metal complexes formed and reduce the charge density of humic and fulvic acids, which makes them more hydrophobic and absorbable (Bratby 2006). The use of coagulants appeared to do a good job of reducing TTHM in particular (suggesting that they are formed from more hydrophobic precursors). Lower $\mathrm{pH}$ yielded better results than higher $\mathrm{pH}$ values. It should be noted here that higher HAA5 values were observed with the higher $\mathrm{pH}$ values, which was unexpected. For this water process, DBP compliance was achieved when DOC was less than $2.5 \mathrm{mg} / \mathrm{L}$ and $U_{254}$ was less than $0.03 \mathrm{abs} / \mathrm{cm}$.

\subsubsection{Agriculture-Influenced Reservoir, AGR}

After the first round of tests, it became apparent that the current treatment in the first stage rapid mix process (alum + acid + baking soda) is not sufficient enough to sustainably achieve

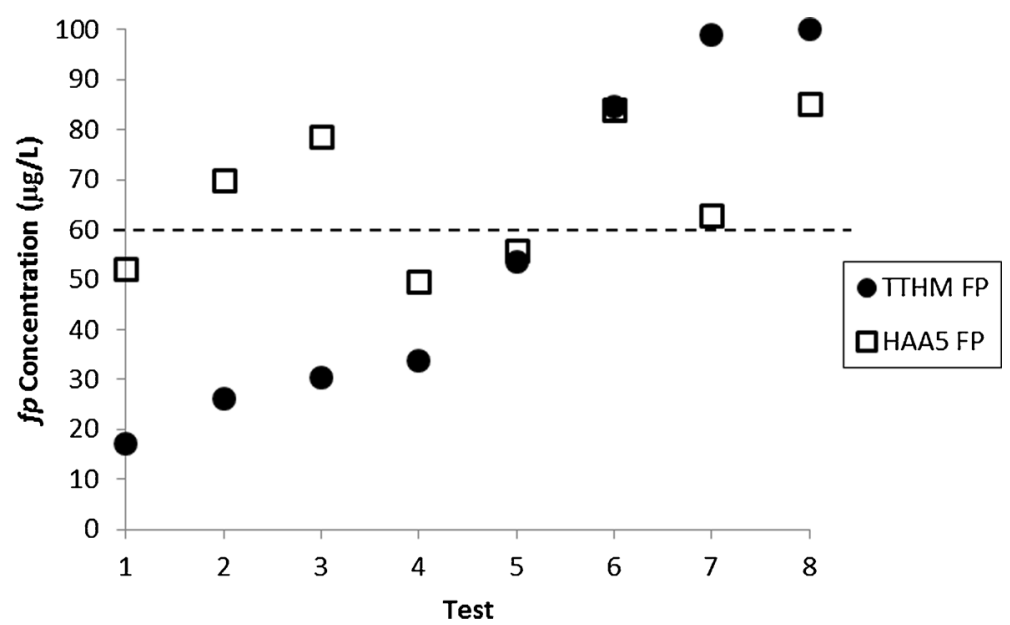

Fig. 4 CTL: top performance combinations for lowest TTHM FP and HAA5 FP values. 1-29Al/48C; 2-43.5Al/24C; 3-43.5Al; 4-29Al/24C; 5-100Fe; 6 14.5Al; 7-100Al; 8-Current treatment (TTHM $\mathrm{MCL}=80 \mathrm{ug} / \mathrm{L} / \mathrm{HAA} 5 \mathrm{MCL}=60 \mathrm{ug} / \mathrm{L})$ 
compliance with EPA standards. When adding ferric chloride to water after carbon addition, the TTHM $f p$ and HAA5 $f p$ were lower than the standards; therefore, future testing focused on using ferric chloride as the main chemical addition.

All of the tests where ferric chloride was the coagulant showed TTHM $f p$ and HAA5fp values below regulatory requirements, whereas the tests with liquid alum were still too high. After trying various chemical combinations the top performance tests were chosen for recommendations based on the highest percent reduction of $\mathrm{UV}_{254}$ and dissolved organic carbon (Fig. 5).

Due to AGR's higher $\mathrm{UV}_{254}$ values in the raw water, it can be assumed that there is a high amount of aromatic organics present in the water. Since coagulation more easily removes aromatic organic matter, allowing mixing with the ferric chloride in the system will allow greater removal. Carbon is not as effective or as necessary to be used.

AGR water responded best to enhanced coagulation using ferric salts. Anticipating the need for $\mathrm{pH}$ adjustment, several alkaline chemicals were used. Baking soda yielded the better DBP reduction results than magnesium hydroxide. For this water process, DBP compliance numbers were achieved when $U_{254}$ was less than $0.03 \mathrm{abs} / \mathrm{cm}$ and DOC was about $3 \mathrm{mg} / \mathrm{L}$.

\subsubsection{Spring-Fed River, SFR}

Since this process currently operates as an enhanced softening process with sodium aluminate as the coagulant, the jar tests for this process were based on modification of this strategy. Sodium aluminate is used typically in only small dosages; therefore, ferric chloride and liquid alum (aluminum sulfate), which are more commonly used in higher doses, were chosen as alternative chemicals. In addition, liquid alum is only effective over a limited $\mathrm{pH}$ range of 6.57.5 and ferric chloride is effective over a wider $\mathrm{pH}$ range of 4-11. However, ferric chloride consumes twice as much alkalinity as alum (US Army Corp of Engineers 2001).

The water used for jar testing was obtained from the raw water from the reservoir. This site was selected in order to consider improvements in chemical use in the upflow clarifier basin.

The lower $\mathrm{UV}_{254}$ values indicate less aromatic organic matter in SFR's raw water. However, the high TTHM $f p$ and HAA5fp concentrations signify there is still a high amount of

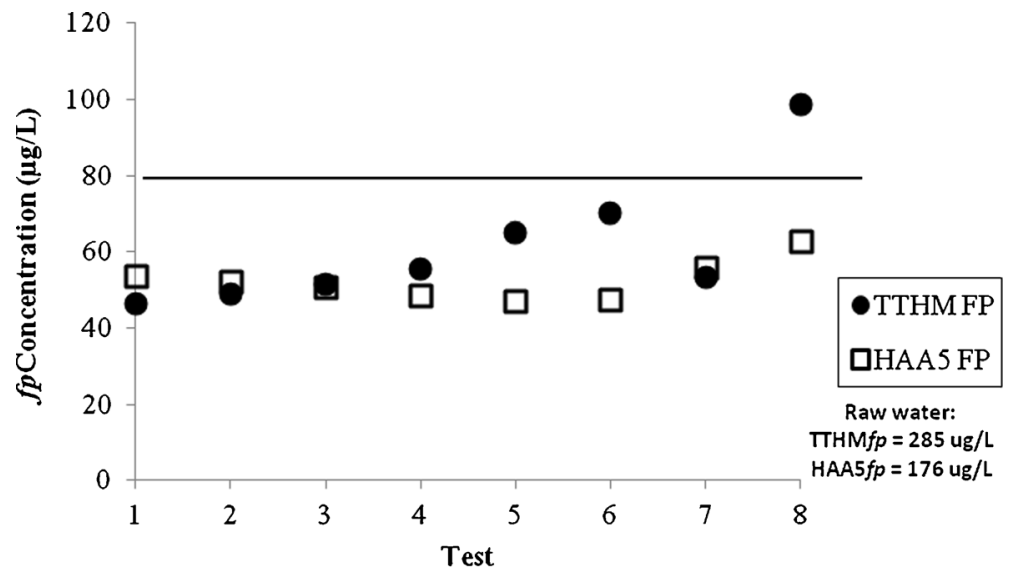

Fig. 5 AGR: top performance combinations for lowest TTHM FP and HAA5 FP values. $1-144 \mathrm{Fe} / 34$ baking soda; 2-144Fe/17 baking soda; 3-144Fe/9baking soda; 4-100 Fe; 5-144Fe/34 $\mathrm{Mg}(\mathrm{OH})_{2} ; 6-144 \mathrm{Fe} /$ $17 \mathrm{Mg}(\mathrm{OH})_{2} ; 7-144 \mathrm{Fe} / 9 \mathrm{Mg}(\mathrm{OH})_{2} ; 8-100 \mathrm{Al}$ 
natural organic matter in the water. For the initial jar tests, the chemical combination of $8 \mathrm{mg} / \mathrm{L}$ sodium aluminate (Al) with $130 \mathrm{mg} / \mathrm{L}$ lime and $9 \mathrm{mg} / \mathrm{L}$ carbon (C) had the lowest HAA5fp, but the TTHM $f p$ concentration was still above the limit of $80 \mu \mathrm{g} / \mathrm{L}$. Further testing was performed to optimize chemical selection in the upflow clarifier to reduce DBP precursors and, ultimately, to reduce TTHM and HAA5 concentrations. The best combination results of these tests (shown in Fig. 6) showed that the combination of ferric salts (Fe) and lime yields the best TTHM $f p$ and HAA5 $f p$ for this facility.

As part of the treatment process, SFR required lime addition $(\sim 300 \mathrm{mg} / \mathrm{L})$ to get $\mathrm{pH}$ of the water above 11 for their precipitation softening process. An increase in $\mathrm{pH}$ typically results in an increase of THM formation but a decrease of total organic halide and HAA formation (Kalscheur et al. 2006). In addition to this treatment requirement, the addition of $100 \mathrm{mg} / \mathrm{L}$ of either ferric salts or aluminum sulfate plus at least $9 \mathrm{mg} / \mathrm{L}$ of carbon yielded the best DBP reductions. The reduction of the DOC below 2.5 seemed to have a more significant impact on DBP reductions than reducing the $\mathrm{UV}_{254}$ since all of the ultraviolet absorbance numbers remained near $0.05 \mathrm{abs} / \mathrm{cm}$. During enhanced softening with an increased $\mathrm{pH}$, both $\mathrm{CaCO}_{3}$ and $\mathrm{Mg}(\mathrm{OH})_{2}$ are positively charged at higher lime $\left(\mathrm{Ca}(\mathrm{OH})_{2}\right)$ and $\mathrm{NaOH}$ doses, therefore yielding a greater affinity for adsorbing negatively charged organic molecules (Russell et al. 2009).

\section{Conclusions}

\subsection{City Lake, CTL}

These tests indicated that none of the individual chemicals gave the total trihalomethane formation potential and five regulated species of haloacetic acid formation potential reduction necessary to be in compliance. Overall, if increased coagulant dosage is feasible for the facility, enhanced coagulation with ferric chloride worked the best for this raw water to achieve effective disinfection by-product precursor reduction. Additionally, this facility benefits greatly from the placement of the pulsator unit in the treatment sequence as indicated by the

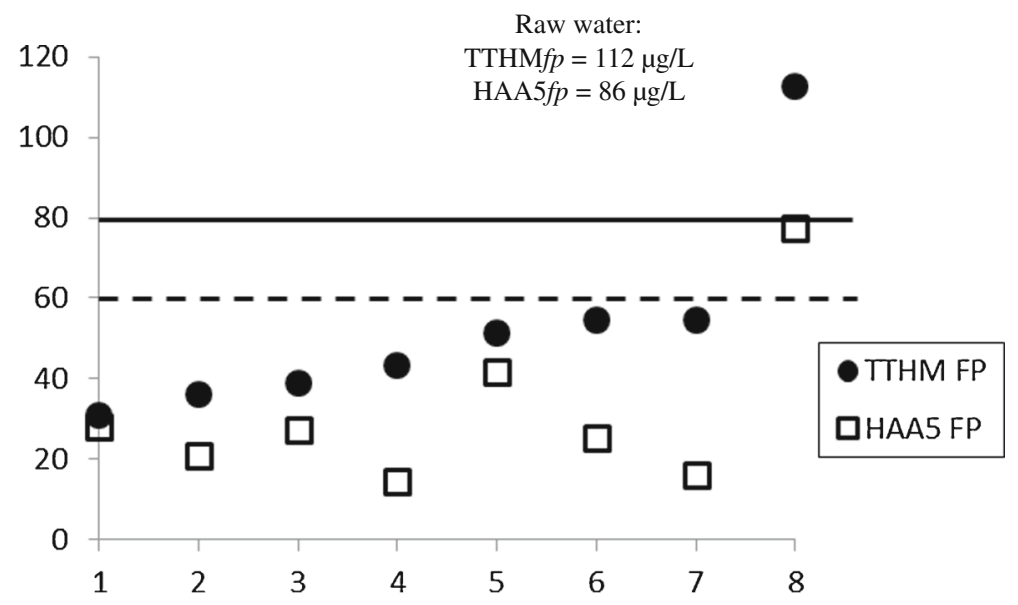

Fig. 6 SFR: top performance combinations for lowest TTHM FP and HAA5 FP values. 1-200Fe; 2-100Al/ 300 lime/9C 3-100Fe/300lime 4-100Fe/300 lime/9C; 5-100Fe; 6-100Al/300lime; 7-150Al; 8 - Current chemical combination 
disinfection by-product compliance numbers consistently below the maximum contaminant level. This process unit allows for the addition of powder activated carbon to be effective because of the additional contact time provided by capture in the sludge blanket.

\subsection{Agriculture-Influenced Reservoir, AGR}

Overall, the first round of testing indicated the current treatment process was not effective at reducing total trihalomethane formation potential and haloacetic acid formation potential concentrations sufficiently. However, with the switch from alum + acid to ferric chloride, the total trihalomethane formation potential and haloacetic acid formation potential values were low enough to be in compliance. Implementation of the strategy by the treatment facility at a pilot scale confirmed that the switch to ferric and monitoring of both dissolved organic carbon and ultraviolet radiation at $254 \mathrm{~nm}$ results in more sustainable disinfection by-product compliance $(70 \mu \mathrm{g} / \mathrm{L}$ of trihalomethanes and $24 \mu \mathrm{g} / \mathrm{L}$ of haloacetic acids).

\subsection{Spring-Fed River, SFR}

All of the top performance combinations had total trihalomethane formation potential and haloacetic acid formation potential values less than needed to be in compliance. A higher amount of coagulant dosing (100-150 mg/L) showed more optimal results than lower dosing $(50 \mathrm{mg} / \mathrm{L})$ indicating that enhanced softening is a better option. In addition, precursor removal was increased when using ferric chloride versus liquid alum.

Raw water characteristics, particularly the values of dissolved organic carbon and ultraviolet radiation at $254 \mathrm{~nm}$, provide some indication of the level of treatment needed to achieve compliance with disinfection by-product regulations. For the surface waters studied (hydrophobic with moderate dissolved organic carbon content) enhanced coagulation with the ferric salts outperformed both aluminum salts and powder activated carbon. The effectiveness of the carbon appeared to be influenced by contact time since the more effective treatment sequence for carbon uses a robust solids contact unit, the Degrémont pulsator, when the other systems have little success with the use of carbon for disinfection by-product precursor reduction.

Acknowledgments This research was partially funded through the former Missouri Technical Assistance Center that was part of the University of Missouri Water Resources Research Center (WRRC) and partially funded by each of the community partners. We thank Dr. Thomas Clevenger, director of WRRC, for access to space and equipment, Dr. Jing Cheng for analysis of water samples for Phase 1 of this project, Mr. Daniel Crosby for his assistance with gathering water samples from each of the facilities, Dr. Robert Reed for his assistance with coordinating with the partner communities, Mr. Roger Sullivan of Marceline, MO for his assistance with the jar testing and treatment strategy guidance, Mr. Steve Reid of Trenton, MO, Mr. Donnie Parsons of Monroe City, and Mr. Larry Howertor of Monroe City for their assistance with sample collection and treatment strategy guidance.

Open Access This article is distributed under the terms of the Creative Commons Attribution License which permits any use, distribution, and reproduction in any medium, provided the original author(s) and the source are credited.

\section{References}

APHA, American Water Works Association, and Water Environment Federation (1998) Standard methods for examination of water \& wastewater, 20th edn. American Health Association, Baltimore

ASTM International (2008) Standard practice for coagulation-flocculation jar test of water. West Conshohocken, PA 
AWWA, American Water Works Association (2010) AWWA overview of stage 2 DBP and LT2ESWT rules. http://www.awwa.org/Government/content.cfm?ItemNumber=47980. Accessed 8 Aug 2010

Bolto B, Dixon D, Eldridge R, King S (2002) Removal of THM precursors by coagulation or ion exchange. Water Res 36(20):5066

Bourbonniere RA (2009) Review of water chemistry research in natural and disturbed peatlands. Can Water Resour J 34(4):393-414

Bratby J (2006) Coagulation and flocculation in water and wastewater treatment. IWA Publishing, Seattle

Chow AT, Dahlgren RA, Zhang Q, Wong PK (2009) Relationships between specific ultraviolet absorbance and trihalomethane precursors of different carbon sources. J Water Supply Res Technol AQUA 57(7):471-480

Chowdhury S (2013) Impact of source waters, disinfectants, seasons and treatment approaches on trihalomethanes in drinking water: a comparison based on the size of municipal systems. Water Environ J 27:197-206

Crozes G, White P, Marshall M (1995) Enhanced coagulation: its effect on NOM removal and chemical costs. J Am Water Works Assoc 87(1):12

Degrémont Technologies Ltd (2013) Superpulsator ${ }^{\mathbb{B}}$. http://www.degremont-technologies.com/dgtech.php? article399. Accessed 10 Feb 2013

DeWolfe J, Dempsey B, Taylor M, Potter JW (2003) Guidance manual for coagulant changeover. AWWA Research Foundation, Denver

Duan J, Cao X, Chen C, Shi D, Li G, Mulcahy D (2012) Effects of $\mathrm{Ca}(\mathrm{OH}) 2$ assisted aluminum sulfate coagulation on the removal of humic acid and the formation potentials of tri-halomethanes and haloacetic acids in chlorination. J Environ Sci 24(9):1609-1615

Ho L, Hainthaler M, Newcombe G (2013) Using UV spectroscopy and molecular weight determinations to investigate the effects of various water treatment processes on NOM removal: Australian Case Study. J Environ Eng 139:117-126

Hobson P, Febris R, Develter E, Linden LG, Burch MD, Brookes JD (2010) Reservior inflow monitoring for improved management of treated water quality-A South Australian experience. Water Resour Manag 24: 4161-4174

Kalscheur KN, Gerwe CE, Kweon J, Speitel GE, Lawler DF (2006) Enhanced softening: effects of source water quality on NOM removal and DBP formation. Am Water Works Assoc 98:11

Liang L, Singer PC (2003) Factors influencing the formation and relative distribution of haloacetic acids and trihalomethanes in drinking water. Environ Sci Technol 37(13):2920-2928

MoTAC (2009) Missouri Technology Assistance Center. http://water.missouri.edu/dbp.htm. Accessed 1 Aug 2010

Qasim SR, Motley EM, Zhu G (2000) Water works engineering: planning, design \& operation. Prentice-Hall, Inc., Upper Saddle River

Reckhow DA, Singer PC, Malcolm RL (1990) Chlorination of humic materials: byproduct formation and chemical interpretations. Environ Sci Technol 24(11):1655-1664

Russell CG, Lawler DF, Speitel GE, Katz LE (2009) Effect of softening precipitate composition and surface characteristics on natural organic matter adsorption. Environ Sci Technol 43:7837-7842

Summers RS, Hooper SM, Shukairy HM, Solarik G, Owen D (1996) Assessing DBP yield: uniform formation conditions. J Am Water Works Assoc 88(6):80

Teixeria MR, Rosa SM, Sousa V (2011) Natural organic matter and disinfection by-products formation potential in water treatment. Water Resour Manag 25:3005-3015

Thompson JD, White MC, Harrington GW, Singer PC (1997) Enhanced softening: factors influencing DBP precursor removal. Am Water Works Assoc 89(June 1997):6

US Army Corp of Engineers (2001) Engineering and design-precipitation/coagulation/flocculation. D. o. t. Army, Washington, DC, p 101

USEPA (2008) Small public water systems and capacity development. http://www.epa.gov/safewater/ smallsystems/basicinformation.html. Accessed 10 Jun 2010

Uyak V, Yavuz S, Toroz I, Ozaydin S, Genceli EA (2007) Disinfection by-products precursors removal by enhanced coagulation and PAC adsorption. Desalination 216:11

Yan M, Wang D, Ni J, Qu J, Yan Y, Chow CWK (2008) Effect of polyaluminum chloride on enhanced softening for the typical organic-polluted high hardness North-China surface waters. Sep Purif Technol 62(2):401-406 